\title{
A AGRICULTURA DO AGRONEGÓCIO E SUA RELAÇÂO COM A INTOXICAÇÃO AGUDA POR AGROTÓXICOS NO BRASIL
}

\section{AGRICULTURE OF AGRIBUSINESS AND RELATIONSHIP TO ACUTE POISONING BY PESTICIDE IN BRAZIL}

\author{
Stephanie Sommerfeld de Lara \\ Mestra em Saúde Coletiva \\ Instituto Federal de Mato Grosso \\ stephanie sommerfeld@hotmail.com \\ Wanderlei Antonio Pignati \\ Doutor em Saúde Pública \\ Universidade Federal de Mato Grosso \\ pignatimt@gmail.com \\ Marta Gislene Pignatti \\ Doutora em Saúde Coletiva \\ Universidade Federal de Mato Grosso \\ martapignatti646@gmail.com \\ Luís Henrique da Costa Leão \\ Doutor em Saúde Pública \\ Universidade Federal de Mato Grosso \\ luisleaoufmt@gmail.com \\ Jorge Mesquita Huet Machado \\ Pós-doutorado em Saúde Coletiva \\ Fundação Oswaldo Cruz \\ jorgemesquista@yahoo.com.br
}

\begin{abstract}
RESUMO
A pulverização de agrotóxicos em larga escala nos monocultivos agrícolas expõe cotidianamente a população residente e trabalhadores a possíveis envenenamentos agudos e/ou crônicos. O objetivo deste trabalho é descrever as intoxicações por agrotóxicos ocorridas no Brasil, Unidades Federadas e especificamente Mato Grosso, e correlacionar esses registros com 0 uso e exposição ambiental a agrotóxicos pulverizados nas lavouras. Trata-se de um estudo epidemiológico, descritivo e ecológico-analítico. Para observar a associação entre os indicadores ambientais e de saúde, foi utilizado a correlação linear de Spearman. Mapas foram criados usando Sistemas de Informação Geográficos. As intoxicações por agrotóxicos ocuparam o segundo lugar dentre todas exógenas e a letalidade a primeira posição. Os envenenamentos por agrotóxicos agrícolas dobraram de valor no período de 2007-2016. O Mato Grosso, Paraná e Rio Grande do Sul foram destaque para o uso de agrotóxicos, enquanto que Espirito Santo, Tocantins e Paraná para as maiores incidências de intoxicação. A correlação foi positiva e significante entre o agravo, o consumo e exposição ambiental a agrotóxicos nas Unidades Federadas e municípios de Mato Grosso. Conclui-se que nas regiões com elevada produção agrícola e pulverização de agrotóxicos também ocorre as maiores incidências de intoxicação. Devido o risco do agravo gerar sequelas temporárias, permanentes e óbitos em trabalhadores e população, a Vigilância em Saúde deve desenvolver ações contínuas para reduzir a exposição aos produtos, e consequentemente, evitar a ocorrência de intoxicações.
\end{abstract}

Palavras-Chave: Exposição a Agrotóxicos. Intoxicação aguda. Saúde Pública.

Recebido em: 28/01/2019

Aceito para publicação em: 16/08/2019 


\begin{abstract}
Large-scale spraying of pesticides on agricultural plantation exposes on a daily basis the resident population and workers to acute and / or chronic poisoning. The objective of this work is to describe official records of poisoning by pesticides in Brazil, Federate Units and specifically Mato Grosso state, and to correlate these records with use and environmental exposure to pesticides sprayed on agricultural crops. It is an epidemiological study, descriptive and ecological-analytical design. To observe the association between environmental and health variables it was used the method supported by Spearman's linear correlation. Maps were made using Geographical Information Systems. Poisoning by pesticides is second-ranked among all exogenous intoxication and lethalness first-ranked. The number of poisoning records by agricultural pesticides has been increased by twice from 2007 to 2016 . The states of Mato Grosso, Paraná and Rio Grande do Sul have presented the highest pesticides use, while Espirito Santo, Tocantins and Paraná recorded the highest incidence of intoxications. The correlation showed positive scores and statistical significance between intoxication and use and environmental exposure to pesticides in both, Brazilian states and municipalities of Mato Grosso. As conclusion, we can say that regions with high agricultural productivity and spraying of large amount of pesticides have the highest intoxication incidence. For this reason, due the risk of temporary and permanent sequelae and deaths of workers and population, Health Surveillance should develop continuous actions to reduce the exposure and consequent occurrence of intoxications.
\end{abstract}

Keywords: Exposure to pesticides. Acute Poisoning. Public Health Surveillance.

\title{
INTRODUÇÃO
}

O Brasil é um dos 10 países com a maior economia mundial, onde o agronegócio é enfatizado como uma das mais importantes fontes geradoras dessa riqueza, devido a elevada produção agropecuária no território (JANK et al., 2005). Em consequência dos interesses de ordem econômica para produção agrícola a qualquer custo, o Brasil também lidera a importação de agrotóxicos, utilizando cerca de $10 \%$ de todo produto do mundo a partir de 2013 , aplicados para 0 controle de doenças de plantas e "pragas" animais ou vegetais (PELAEZ et al., 2015).

Estima-se que a pulverização de agrotóxicos seja de aproximadamente 900 milhões de litros por ano no Brasil, onde $76 \%$ desse consumo concentra-se nos cultivos de exportação de soja, milho e cana (PIGNATI et al., 2017). A literatura aponta que os agrotóxicos agrícolas são os mais tóxicos, ou seja, os que mais geram envenenamentos e mortes, e uma parcela considerável destes produtos são proibidos na União Europeia, mas continuam sendo utilizados no Brasil, mesmo comprovado cientificamente seus prejuízos para a saúde e meio ambiente (BOCHNER, 2007; CARNEIRO et al., 2015; MOSTAFALOU e ABDOLLAHI, 2017).

Diante do cenário, nos deparamos com o desfecho mais visível dos impactos dos agrotóxicos na saúde humana, as intoxicações agudas. O curto período entre a exposição e o adoecimento possibilita identificar, realizar o diagnóstico e em poucas horas notificar o caso (FARIA et al., 2007). MALASPINA et al. (2011), afirma que em 2010, este agravo já ocupava a segunda posição dentre as intoxicações exógenas notificadas no Sistema de Informação de Agravos de Notificação (SINAN) do Ministério da Saúde.

Globalmente, as intoxicações são consideradas um significativo problema de saúde pública, devido aos gastos, anos perdidos de vida e número de óbitos (WHO, 2018). A intoxicação aguda por agrotóxicos pode ser classificadas na forma leve, moderada ou grave, com ocorrência em até 48 horas, com sinais e sintomas de náuseas, tonturas, vômitos, desorientação, dificuldade respiratória, sudorese, salivação excessiva, diarreia, até coma e morte, a depender da quantidade e toxicidade de veneno absorvido pela pele, via respiratória e/ou digestiva (OPAS, 1997; BRASIL, 2006). 
Além da aguda, as intoxicações subagudas e crônicas podem aparecer a longo prazo, ocasionadas por repetidas exposições a agrotóxicos com manifestações clínicas inespecíficas, principalmente quando há exposição múltipla aos produtos. Esse fato, comum na agricultura brasileira, geralmente causa danos irreversíveis, como câncer, malformação, lesões renais, hepáticas, distúrbios endócrinos, neurológicos entre outros. No entanto, na prática dos serviços de saúde, torna-se um desafio estabelecer a associação causal com os agrotóxicos, sendo alvo de maior atenção nos últimos anos para alguns estados Brasileiros, dentre eles o Paraná.

A problemática levantada neste estudo é acerca das regiões de elevada área, produção agrícola e consequentemente uso de agrotóxicos. Pressupõe-se que o processo produtivo e econômico do agronegócio adotado no país tem desencadeado padrões no nível de saúde da população que reside nestes locais. Tanto os trabalhadores agrícolas, do agronegócio e moradores da região estão expostos a vários tipos de agrotóxicos cotidianamente, pela via ambiental, ocupacional e/ou alimentar.

Este modelo de produção tem deixado resíduos de agrotóxicos detectados nos fluidos corporais de sangue, urina, leite materno de humanos e também no ar que respiram, água que bebem, alimentos e animais que consomem nestas regiões (BELO et al., 2012; MOREIRA et al., 2012; PALMA et al., 2014; BESERRA, 2017; OLIVEIRA, 2018; LOPES e ALBURQUERQUE, 2018).

A ocorrência das intoxicações acompanha a produção agrícola do agronegócio e uso de agrotóxicos? De fato, as intoxicações agudas por agrotóxicos representam a ponta do iceberg que estes produtos produzem de efeitos negativos à saúde humana, e dessa forma, servem de alerta para indicar indivíduos e locais onde as intoxicações crônicas podem estar subnotificadas. Neste sentido, a combinação de base de dados por meio de estudos ecológicos pode auxiliar na geração de hipóteses de como o contexto ambiental pode afetar a saúde da população (MEDRONHO et al., 2011).

Diante do exposto, este artigo visou descrever as intoxicações agudas por agrotóxicos, mapeá-las e associa-las com a produção agrícola e uso de agrotóxicos nas Unidades Federadas e municípios de Mato Grosso.

\section{METODOLOGIA}

Trata-se de um estudo epidemiológico observacional, elaborado em duas partes. A primeira de caráter descritivo, acerca das intoxicações exógenas, sendo enfatizado as ocasionadas por agrotóxicos. A segunda parte, composta por um estudo ecológico analítico, associando as intoxicações por agrotóxicos agrícolas ao consumo e exposição ambiental destes produtos nas Unidades Federadas e municípios de Mato Grosso.

Os estudos descritivos visam determinar a distribuição de doenças ou condições relacionadas à saúde, segundo o tempo, o lugar e/ou as características dos indivíduos, enquanto que os ecológicos servem como geradores de hipóteses, avaliam intervenções e são delineados para examinar a existência de associação entre uma exposição e uma doença, ou seja, como os contextos sociais e ambientais podem afetar a saúde desses grupos. São realizados a partir da combinação base de dados de grandes populações em uma área definida. Por tratar-se de uma associação observada entre agregados, são passiveis de falácia, pois não significa, obrigatoriamente, que a mesma associação ocorra em nível de indivíduos (JEKEL et al., 2005, MEDRONHO et al., 2011).

Para a composição deste estudo, os dados de intoxicação exógena foram obtidos no Sistema de Informação de Agravos e Notificação (SINAN) do Ministério da Saúde (MS) referente as intoxicações por agrotóxicos agrícolas, veterinários, raticidas, domésticos e de saúde pública no período de 2007 a 2016 (BRASIL, 2018).

$\mathrm{Na}$ primeira parte descritiva do estudo, gerou-se taxas de incidência e letalidade anuais de intoxicação de todos os grupos de agrotóxicos (agrícolas, veterinários, raticidas, domésticos e de saúde pública) na série histórica de 2007 a 2016 para o Brasil. Para as Unidades Federadas, foi calculada uma incidência média de intoxicação para agrotóxicos agrícolas, no ano de 2012 a 
2015, de acordo com o cálculo: média dos casos de intoxicação por agrotóxicos agrícolas notificados no período de 2012 a 2015 nas Unidades Federadas, dividido pela média populacional do mesmo período e local, multiplicado pela constante de 1 milhão de habitantes. Foi realizado o mesmo cálculo para os municípios de Mato Grosso, porém, utilizando a constante de 100 mil habitantes. Esse indicador possibilitou expressar a incidência anual do agravo a saúde, pois a média corrigiu variações de notificações que pode ocorrer entre os anos. As taxas de letalidade foram calculadas a partir da proporção de óbitos por intoxicação e o número dos intoxicados, expressos por uma constante de mil intoxicados.

Foi adquirido no banco de dados de Produção Agrícola Municipal (PAM) do Sistema IBGE de Recuperação Automática do Instituto Brasileiro de Geografia e Estatística (IBGE-SIDRA), para o ano de 2015 a área plantada de 21 lavouras agrícolas predominantes no agronegócio brasileiro. Após isto, multiplicou-se a área plantada das lavouras pelo total de litros de agrotóxicos estipulado para cada monocultivo, conforme a metodologia de Pignati et al. (2017). Gerou então, o indicador do consumo de agrotóxicos agrícolas estimado para cada Unidade Federada e municípios de Mato Grosso.

Para a segunda parte do artigo, do estudo ecológico, foi utilizado os indicadores ambientais: 1) o consumo total de litros de agrotóxicos agrícolas pulverizados e 2) a exposição ambiental a agrotóxicos por habitante, oriundo do cálculo: quantidade de litros de agrotóxicos utilizados em determinado período e local, dividido pela população residente no mesmo período e local, sendo adotado neste estudo o ano de 2015.

O indicador de saúde utilizado foi a incidência média de intoxicação aguda por agrotóxicos nos anos de 2012 a 2015, para Unidades Federadas e Municípios do Mato Grosso, previamente calculados na parte descritiva do artigo.

Foi utilizado a inferência estatística da correlação de Spearman, visto que a distribuição dos dados fora não-paramétrica, indicado pelo teste de Kolmogorov-Smirnov. Utilizou-se a significância estatística de $95 \%$. As variáveis independentes foram as ambientais (consumo de agrotóxicos e exposição ambiental a agrotóxicos), e dependente, a de saúde, incidência média de intoxicação por agrotóxicos agrícolas no período de 2012 a 2015.

Para a apresentação dos resultados, utilizou-se tabelas e mapas temáticos no programa ArcGis 10.1. Os dados são secundários e de domínio público registrados no SINAN, desse modo, dispensou-se a submissão ao Comitê de Ética em Pesquisa para este estudo, conforme a Resolução 510/16 do Conselho Nacional de Saúde.

\section{RESULTADOS E DISCUSSÃO}

\section{Panorama brasileiro das intoxicações e consumo de agrotóxicos agrícolas}

No período de 2007 a 2016 registrou-se 597.498 intoxicações exógenas no SINAN, e o agente tóxico com o maior número de ocorrências foi por medicamento; posteriormente pelo grupo de agrotóxicos (agrícola, veterinário, raticida, doméstico e saúde pública); em terceiro as intoxicações ignoradas e em quarto as drogas de abuso (Tabela 1).

A segunda posição ocupada pelo grupo de agrotóxicos, representa $16 \%$ das ocorrências de intoxicação exógena no período de 2007 a 2016. Foram registradas 96.534 intoxicações no Brasil, equivalendo a 9.653 brasileiros intoxicados por agrotóxicos ao ano ou 26 por dia.

Dentre o grupo de agrotóxicos, os raticidas e agrotóxicos agrícolas foram os agentes tóxicos que mais ocasionaram intoxicações agudas no Brasil, com aproximadamente 40 mil casos para o primeiro grupo e 36 mil para o segundo. Os agrotóxicos domésticos ocasionaram neste período 11 mil intoxicações e produtos veterinários cerca de 8 mil, e por último, os agrotóxicos usados na saúde pública foram responsáveis por aproximadamente 2 mil intoxicações.

Foi observado o aumento do número dos casos de intoxicação em todos os agentes tóxicos, os agrotóxicos domésticos e veterinários triplicaram as ocorrências, e raticidas, agrotóxicos agrícolas e de Saúde Pública dobraram de valor. 
Um marco que pode ter relação com o aumento da notificação foi a implantação da Vigilância em Saúde de Populações Expostas a Agrotóxicos (VSPEA) a partir de 2012, nos estados e Distrito Federal para execução das ações de prevenção, proteção e promoção da saúde, que pode ter aumentado a sensibilidade na captação de novos casos, haja visto que o agravo tornou-se de notificação compulsória em 2011 (BRASIL, 2016). A liderança mundial do Brasil a partir de 2008 no consumo de agrotóxicos para a agricultura é outro fator que pode ter influenciado no aumento de casos.

Ressalta-se que a estimativa de subnotificação em 1990 era de 1 caso registrado a cada 50, ou seja, $2 \%$ dos casos ocorridos eram notificados, geralmente os mais graves e que necessitaram de internação, e, portanto, representavam apenas uma fração do problema (OMS, 1990).

Tratando-se de envenenamentos por agrotóxicos agrícolas utilizados no agronegócio, existem relatos que sugerem que estes sejam invisibilizados intencionalmente e silenciados por pressões políticas e de gestão, por priorizarem a economia em detrimento da saúde da população (NASRALA et al., 2014; CARNEIRO et al., 2015).

A subnotificação das intoxicações prejudica ações de vigilância à saúde e impedem o acesso dos trabalhadores e residentes aos seus direitos, à informação da sua real situação de saúde e segurança no trabalho, além de impossibilitar a quantificação de gastos em despesas médicas, previdência social que são geradas decorrentes dos envenenamentos (PARANÁ, 2013).

No presente artigo, as incidências anuais de intoxicação aguda por todos os grupos de agrotóxicos acompanharam o crescimento, praticamente dobrando o número de casos, passando de 27 para 57 envenenamentos a cada 1 milhão de habitantes no período de 2007 a 2016.

Os mais expostos a agrotóxicos são os trabalhadores da cadeia do agronegócio, posteriormente os familiares desses trabalhadores e moradores do entorno de ambientes contaminados por agrotóxicos, seguido dos consumidores de alimentos e água contaminada com resíduos e por fim, a população em geral que tem acesso aos produtos (BRASIL, 2012).

O grupo de agrotóxicos concentrou $39 \%$ de todos os óbitos por intoxicação exógena, totalizando 3.196 mortes. As taxas de letalidade foram três vezes superiores aos outros agentes tóxicos somados (medicamentos, drogas de abuso, alimentos e bebidas, produtos químicos, plantas tóxicas, etc.). Os óbitos continuaram crescendo ao longo dos anos, porém, a letalidade por agrotóxicos apresentou tendência de decréscimo na série histórica e estabilizou-se de 2011 a 2016 com 30 óbitos a cada mil intoxicado por agrotóxicos, ou seja, 3 mortes a cada 100 intoxicações (Tabela 1).

Em termos numéricos, os grupos de agrotóxicos juntos se configuram como o segundo principal agente tóxico nas intoxicações exógenas. Entretanto, apresenta a maior letalidade como comprovado em outros estudos, demonstrando sua periculosidade, pois todos são venenos, biocidas, agem matando as "pragas", diferente dos outros grupos de intoxicação, como por exemplo o medicamento, que ocupa a primeira posição das intoxicações, mas o objetivo final não é ocasionar a morte (FARIA et al., 2007; BOCHNER, 2007)

Segundo BOCHNER (2007), a letalidade se apresenta diferente em cada grupo de agrotóxicos, onde a menor foi por agrotóxicos de uso doméstico, e maior por agrotóxicos agrícolas, ou seja, intoxicar-se com agrotóxico agrícola decorre em maiores chances de óbito. A autora recomenda que cada óbito deva ser tratado como evento sentinela, pois existe outros trabalhadores exercendo as mesmas funções e expostos aos riscos desses produtos tóxicos (BOCHNER, 2015).

Os estados brasileiros que se destacaram com o maior número de intoxicação por todos os grupos de agrotóxicos foram São Paulo, Paraná e Minas Gerais com mais de 10 mil envenenamentos no período de 2007 a 2016 (Tabela 2). Nestes estados elencados, o grupo de agrotóxicos agrícolas foi mais frequente no Paraná com 5.209 casos, enquanto nos demais o raticida apresentou maior número de notificação. Essas notificações podem ser justificadas por serem estados populosos. Dessa forma, capta-se mais casos de intoxicações por meio da vigilância, porém, este número também pode refletir a produção agrícola, devido nessas localidades haver maior chance de uso de agrotóxicos. 
Stephanie Sommerfeld de Lara

Wanderlei Antonio Pignati Marta Gislene Pignatti

A agricultura do agronegócio e sua relação com a intoxicação aguda por agrotóxicos no Brasil

Tabela 1 - Número absoluto, taxas de incidência, óbitos e letalidade das intoxicações aguda por grupos de agrotóxicos e demais agentes tóxicos no Brasil, período de 2007 a 2016.

\begin{tabular}{|c|c|c|c|c|c|c|c|c|c|c|c|}
\hline Anos & 2007 & 2008 & 2009 & 2010 & 2011 & 2012 & 2013 & 2014 & 2015 & 2016 & Total \\
\hline \multicolumn{12}{|c|}{ Agentes tóxicos } \\
\hline Medicamento & 9.353 & 12.061 & 15.298 & 18.023 & 25.126 & 31.555 & 37.081 & 39.987 & 40.662 & 43.154 & 272.300 \\
\hline Ignorado & 5.270 & 4.747 & 6.043 & 5.930 & 7.124 & 10.114 & 11.058 & 11.241 & 10.728 & 10.741 & 82.996 \\
\hline Drogas abuso & 1.011 & 1.868 & 3.047 & 3.873 & 6.414 & 9.279 & 12.124 & 13.313 & 12.234 & 12.594 & 75.757 \\
\hline Alimento/bebida & 2.077 & 2.974 & 4.335 & 5.422 & 7.627 & 9.424 & 9.294 & 9.463 & 8.761 & 7.696 & 67.073 \\
\hline Raticida & 1.971 & 2.397 & 2.824 & 3.381 & 4.440 & 5.038 & 4.815 & 5.184 & 5.109 & 4.631 & 39.790 \\
\hline Agrícola & 2.180 & 2.425 & 2.709 & 2.988 & 3.422 & 3.800 & 4.915 & 4.610 & 4.348 & 4.304 & 35.701 \\
\hline Doméstico & 442 & 538 & 764 & 860 & 1.093 & 1.297 & 1.587 & 1.555 & 1.602 & 1.572 & 11.310 \\
\hline Prod. veterinário & 333 & 437 & 472 & 576 & 766 & 909 & 990 & 1.143 & 1.143 & 1.092 & 7.861 \\
\hline Saúde pública & 103 & 80 & 163 & 164 & 225 & 179 & 276 & 231 & 232 & 219 & 1.872 \\
\hline Demais agentes & 4.147 & 5.102 & 5.726 & 6.551 & 9.013 & 10.825 & 15.465 & 14.043 & 14.064 & 14.436 & 99.372 \\
\hline \multicolumn{12}{|c|}{ Total de intoxicações agudas } \\
\hline Agrotóxicos & 5.029 & 5.877 & 6.932 & 7.969 & 9.946 & 11.223 & 12.583 & 12.723 & 12.434 & 11.818 & 96.534 \\
\hline Outras & 21.858 & 26.752 & 34.449 & 39.799 & 55.304 & 71.197 & 85.022 & 88.047 & 86.449 & 88.621 & 597.498 \\
\hline \multicolumn{12}{|c|}{ Taxas de incidência de intoxicações agudas por 1 milhão de habitantes } \\
\hline Agrotóxicos & 27,3 & 31,0 & 36,2 & 41,8 & 51,7 & 57,9 & 62,6 & 62,7 & 60,8 & 57,3 & - \\
\hline Outras & 118,8 & 141,1 & 179,9 & 208,7 & 287,5 & 367,0 & 422,9 & 434,2 & 422,8 & 430,0 & - \\
\hline \multicolumn{12}{|c|}{ Total de óbitos por intoxicações agudas } \\
\hline Agrotóxicos & 218 & 227 & 262 & 341 & 373 & 341 & 368 & 329 & 382 & 355 & 3.196 \\
\hline Outras & 152 & 234 & 245 & 338 & 459 & 496 & 854 & 653 & 809 & 820 & 5.060 \\
\hline \multicolumn{12}{|c|}{ Taxas de letalidade por mil intoxicados } \\
\hline Agrotóxicos & 43,3 & 38,6 & 37,8 & 42,8 & 37,5 & 30,4 & 29,2 & 25,9 & 30,7 & 30,0 & - \\
\hline Outras & 7,0 & 8,7 & 7,1 & 8,5 & 8,3 & 7,0 & 10,0 & 7,4 & 9,4 & 9,3 & - \\
\hline \multicolumn{12}{|c|}{ Utilização de agrotóxicos em milhões de litros } \\
\hline $\begin{array}{l}\text { Agrotóxicos } \\
\text { agrícolas }^{*}\end{array}$ & 686,4 & 673,9 & 725 & 827,8 & 852,8 & 478,9 & 508,6 & 543,7 & 877,1 & 911,7 & - \\
\hline
\end{tabular}

Legenda - *Estimado a partir das 4 principais culturas do agronegócio brasileiro: soja, milho, cana e algodão, segundo metodologia de Pignati et al. (2017). 
A agricultura do agronegócio e sua relação com a

Tabela 2 - Número absoluto das intoxicações aguda por agrotóxicos segundo grupos tóxicos e Unidades Federadas do Brasil, período de 2007 a 2016.

\begin{tabular}{|c|c|c|c|c|c|c|}
\hline \multirow{2}{*}{ Região e UF } & \multicolumn{5}{|c|}{ Grupos de agrotóxicos } & \multirow{2}{*}{$\begin{array}{l}\text { Total das } \\
\text { intoxicações por } \\
\text { agrotóxicos }\end{array}$} \\
\hline & Agrícola & Doméstico & $\begin{array}{l}\text { Saúde } \\
\text { pública }\end{array}$ & Raticida & Veterinário & \\
\hline \multicolumn{7}{|l|}{ Norte } \\
\hline$A C$ & 12 & 7 & 1 & 21 & 0 & 41 \\
\hline AM & 64 & 80 & 9 & 124 & 16 & 293 \\
\hline AP & 1 & 2 & 0 & 41 & 1 & 45 \\
\hline PA & 185 & 97 & 9 & 395 & 33 & 719 \\
\hline RO & 511 & 104 & 7 & 239 & 99 & 960 \\
\hline $\mathrm{RR}$ & 31 & 33 & 3 & 145 & 28 & 240 \\
\hline TO & 652 & 326 & 112 & 672 & 260 & 2.022 \\
\hline \multicolumn{7}{|l|}{ Nordeste } \\
\hline $\mathrm{AL}$ & 504 & 191 & 20 & 680 & 173 & 1.568 \\
\hline BA & 1.043 & 364 & 89 & 1.473 & 249 & 3.218 \\
\hline CE & 1.585 & 328 & 32 & 982 & 264 & 3.191 \\
\hline MA & 143 & 47 & 22 & 258 & 42 & 512 \\
\hline PB & 130 & 139 & 53 & 440 & 75 & 837 \\
\hline PE & 2.466 & 797 & 56 & 2.058 & 357 & 5.734 \\
\hline $\mathrm{PI}$ & 159 & 87 & 22 & 274 & 82 & 624 \\
\hline $\mathrm{RN}$ & 37 & 46 & 8 & 138 & 18 & 247 \\
\hline SE & 53 & 111 & 5 & 311 & 55 & 535 \\
\hline \multicolumn{7}{|l|}{ Centro-Oeste } \\
\hline DF & 87 & 127 & 1 & 365 & 33 & 613 \\
\hline GO & 1.371 & 556 & 67 & 1.892 & 530 & 4.416 \\
\hline MS & 461 & 304 & 63 & 535 & 311 & 1.674 \\
\hline MT & 695 & 254 & 51 & 463 & 189 & 1.652 \\
\hline \multicolumn{7}{|l|}{ Sudeste } \\
\hline ES & 1.698 & 317 & 78 & 654 & 201 & 2.948 \\
\hline MG & 3.197 & 990 & 175 & 5.511 & 1.147 & 11.020 \\
\hline RJ & 305 & 126 & 79 & 991 & 77 & 1.578 \\
\hline SP & 3.576 & 1.534 & 206 & 7.746 & 1.089 & 14.151 \\
\hline \multicolumn{7}{|l|}{ Sul } \\
\hline PR & 5.209 & 1.759 & 131 & 4.742 & 1.039 & 12.880 \\
\hline RS & 927 & 223 & 42 & 289 & 139 & 1.620 \\
\hline SC & 1.958 & 651 & 30 & 1.294 & 300 & 4.233 \\
\hline Total & 27.060 & 9.600 & 1.371 & 32.733 & 6.807 & 77.571 \\
\hline
\end{tabular}


Ao analisar as intoxicações somente por agrotóxicos agrícolas entre 2012 a 2015, observou-se que a posição dos estados foi alterada (Tabela 3). Minas Gerais apresentou a maior média de registro, com 657 casos por ano, posteriormente Paraná (619) e São Paulo (596). Para comparar a ocorrência da intoxicação por agrotóxicos agrícolas entre os estados brasileiros, foi relativizado os casos pela população, de modo que os dados expressaram a taxa média anual do período. A maior incidência localizou-se no Espírito Santo, com 83 casos a cada 1 milhão de habitantes por ano, Tocantins com 77, Paraná e Goiás com 56 e 41, respectivamente.

A área de monocultivos agrícolas e utilização de agrotóxicos obtidos pela metodologia de Pignati et al. (2017) apontaram os estados de Mato Grosso, Paraná, Rio Grande do Sul, Goiás e São Paulo com as maiores quantidades de agrotóxicos pulverizados (Tabela 3 e Figura 1), com mais de 60 milhões de litros pulverizados em cada estado. Dessa forma, Mato Grosso utilizou em termos de proporção $23 \%$ de todo o agrotóxico agrícola do país, seguido do Paraná (15\%), Rio Grande do Sul (14,8\%), Goiás (8,3\%) e São Paulo (6,8\%).

Conforme o Boletim Epidemiológico do Ministério da Saúde, acerca das intoxicações por glifosato, o herbicida mais utilizado no mundo, os estados do Paraná e Espirito Santo foram destaque para os envenenamentos na zona rural, enquanto que na zona urbana e periurbana, as maiores incidências ocorreram em Santa Catarina, Paraná, Espirito Santo, Goiás e Tocantins. Ao total no Brasil, um terço das intoxicações por glifosato foram relacionadas ao uso agrícola, onde $25 \%$ decorreram de lavouras de soja, milho e cana, os principais cultivos de exportação (BRASIL, 2018).

Tais dados colaboram com os achados deste estudo, pois ocorreu nos mesmos estados as maiores incidências de intoxicação por agrotóxicos agrícolas, com exceção de Santa Catarina, sugerindo que o processo produtivo agrícola pode estar refletindo na ocorrência das intoxicações de modo geral, ultrapassando as barreiras do campo para a área urbana. Esse herbicida compõe a segunda classe de agrotóxicos mais utilizada na agricultura, e seu uso é proibido em área urbana, embora no estudo citado tenha maior incidência nesta zona (BRASIL, 2015).

Os custos com as intoxicações compõem outro ponto a ser discutido. O estado do Paraná consumiu $15 \%$ de todo agrotóxico agrícola do país e possui a terceira maior incidência de intoxicação neste estudo. Autores constataram que para cada dólar gasto em agrotóxicos, aproximadamente US $\$ 1,28$ podem ser gastos em cuidados de saúde e licença por doença por envenenamento ocupacional (SOARES e PORTO, 2012). Provavelmente o Sistema Único de Saúde arca com as maiores despesas decorrentes das intoxicações agudas e crônicas desse modelo de produção, além disso, o agronegócio obtém isenções fiscais em subsídios do Estado previstos na Lei Kandir (BRASIL, 1996). Ainda, perante a relevância epidemiológica que este agravo tem no território Paranaense, o estado tornou-se pioneiro no protocolo de avaliação e diagnóstico das intoxicações crônicas por agrotóxicos, servindo de modelo para o Brasil (PARANÁ, 2018).

Em outros países, como por exemplo no Nepal, constatou-se que os custos estimados de intoxicação aguda em agricultores devido o uso de agrotóxicos representou quase um terço dos custos anuais dos cuidados de saúde (ATREYA, 2008). Esta situação nos leva a questionar o modelo produtivo da agricultura vigente no brasil. Esperar que os trabalhadores e população em geral comecem a adoecer para depois colocar em prática ações de vigilância faz parte de uma lógica perversa, que prestigia o mercado e o capital em detrimento da saúde das pessoas (BOCHNER, 2015).

Dentre os 50 agrotóxicos agrícolas mais utilizados no Brasil, 22 são proibidos na União Europeia, seja pelo potencial tóxico, ou seus efeitos teratogênicos, carcinogênicos, mutagênicos e disruptores endócrinos (CARNEIRO et al., 2015). A lei brasileira de 7.802/98 proíbe o registro de agrotóxicos que ocasione tais efeitos à saúde humana, ou que cause danos ambientais, porém, em meio de uma "emergência fitossanitária", onde não constatado em território brasileiro um produto para o enfrentamento da emergência, agrotóxicos não registrados podem ser importados e utilizados pelo período de tempo necessário, desde que previamente autorizado pelos órgãos federais competentes. Esta exceção possibilita a entrada de agrotóxicos que trazem prejuízos à saúde humana e meio ambiente (BRASIL, 1989; 2002; IBAMA, 2015; DARONCHO, 2017). 
Tabela 3 - Indicadores ambientais do consumo de agrotóxico, exposição ambiental a agrotóxicos, média e incidência média de intoxicações aguda por agrotóxicos agrícolas por Unidade Federada, período de 2012 a 2015 utilizados para correlação estatística.

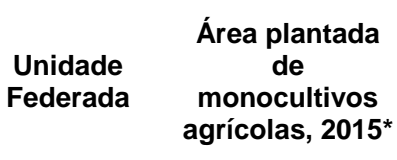

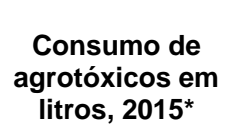

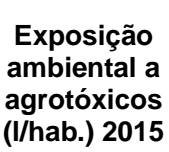

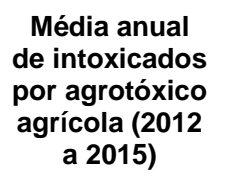

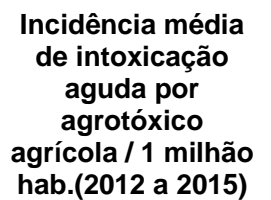

da incidência

\begin{tabular}{|c|c|c|c|c|c|c|}
\hline ES & 593.627 & 5.456 .549 & 1,4 & 318,5 & 83,6 & $1^{0}$ \\
\hline TO & 1.173 .302 & 17.403 .387 & 11,8 & 113,75 & 77,0 & $2^{\circ}$ \\
\hline PR & 10.255 .468 & 135.470 .543 & 12,4 & 619,5 & 56,5 & $3^{\circ}$ \\
\hline GO & 5.830 .192 & 75.135 .233 & 11,7 & 263,75 & 41,0 & $4^{0}$ \\
\hline$A L$ & 417.845 & 2.755 .645 & 0,8 & 134,25 & 40,9 & $5^{0}$ \\
\hline PE & 763.751 & 4.490 .610 & 0,5 & 374,75 & 40,8 & $6^{\circ}$ \\
\hline sc & 1.481 .843 & 23.918 .055 & 3,6 & 255,25 & 38,4 & $7^{0}$ \\
\hline RO & 568.795 & 6.910 .076 & 4 & 64,5 & 37,7 & $8^{\circ}$ \\
\hline MG & 5.130 .624 & 52.731 .202 & 2,6 & 657 & 32,0 & $9^{\circ}$ \\
\hline MS & 4.665 .446 & 58.029 .601 & 22,4 & 80,75 & 31,2 & $10^{\circ}$ \\
\hline MT & 13.980 .996 & 207.735 .607 & 65 & 89 & 27,8 & $11^{\circ}$ \\
\hline CE & 997.257 & 6.551 .303 & 0,7 & 232,5 & 26,5 & $12^{\circ}$ \\
\hline DF & 154.322 & 1.838 .655 & 0,7 & 51,75 & 18,5 & $13^{\circ}$ \\
\hline $\mathbf{R R}$ & 56.806 & 763.059 & 1,6 & 8 & 16,3 & $14^{\circ}$ \\
\hline BA & 3.643 .888 & 49.108 .595 & 3,3 & 213,5 & 14,3 & $15^{\circ}$ \\
\hline SP & 8.136 .504 & 61.797 .269 & 1,4 & 596 & 13,7 & $16^{\circ}$ \\
\hline RS & 8.543 .105 & 133.788 .693 & 12,1 & 135,75 & 12,2 & $17^{\circ}$ \\
\hline PB & 278.061 & 1.631 .397 & 0,4 & 35,25 & 9,0 & $18^{\circ}$ \\
\hline PI & 1.416 .818 & 17.358 .130 & 5,4 & 24,5 & 7,7 & $19^{\circ}$ \\
\hline SE & 308.188 & 2.922 .050 & 1,3 & 12,5 & 5,7 & $20^{\circ}$ \\
\hline PA & 762.574 & 9.443 .170 & 1,2 & 32,5 & 4,0 & $21^{\circ}$ \\
\hline AM & 36.145 & 306.916 & 0,1 & 11,5 & 3,0 & $22^{\circ}$ \\
\hline RJ & 133.257 & 1.014 .804 & 0,1 & 45,5 & 2,8 & $23^{\circ}$ \\
\hline AC & 73.363 & 584.454 & 0,7 & 2 & 2,6 & $24^{\circ}$ \\
\hline MA & 1.627 .532 & 20.649 .982 & 3 & 14,5 & 2,1 & $25^{\circ}$ \\
\hline $\mathbf{R N}$ & 175.913 & 986.017 & 0,3 & 6,25 & 1,9 & $26^{\circ}$ \\
\hline AP & 21.514 & 292.838 & 0,4 & 0,25 & 0,3 & $27^{\circ}$ \\
\hline Total & 71.227.136 & $899.073 .840,70$ & 4,5 & 4393,25 & 21,9 & \\
\hline
\end{tabular}

Fonte - *Pignati et al. (2017). 
A figura $1 \mathrm{~A}$ representa a área plantada de monocultivos agrícolas e respectivos litros pulverizados de agrotóxicos, onde pode-se observar concentrações nas regiões sul, sudeste e centro-oeste. $\mathrm{Na}$ figura $1 \mathrm{~B}$, o consumo dos agrotóxicos foi distribuído junto às incidências médias de intoxicação aguda por agrotóxicos agrícolas, sendo representando pela cor mais escura maior o uso de agrotóxicos, e o tamanho do círculo correspondente as taxas de incidência. As concentrações das maiores incidências de intoxicação estiveram nas regiões com elevado consumo de agrotóxicos, com exceção para alguns estados brasileiros, como observado no mapa. Destaca-se o estado do Paraná e Goiás que apresentaram elevado consumo de agrotóxicos e maiores incidências de intoxicação por agrotóxicos agrícolas (Tabela 3).

Mato Grosso liderou a maior exposição ambiental da população aos agrotóxicos, com 65 litros por habitante correspondendo 14 vezes mais que a média brasileira, seguido de Mato Grosso do Sul (22,4 L.hab. $\left.{ }^{-1}\right)$, Paraná (12,4 L.hab. $\left.{ }^{-1}\right)$, Rio Grande do Sul (12,1 L.hab. $\left.{ }^{-1}\right)$ Tocantins e Goiás (L.hab.- ${ }^{-1}$ ) e Piauí (5,4 L.hab.- ${ }^{-1}$ ). Estes sete estados apresentaram as maiores exposições ambientais devido a maior área plantada e utilização de agrotóxicos, significando que os moradores residentes nestes locais estão expostos a uma carga muito acima dos demais brasileiros, onde a média nacional constatada foi de 4,5 litros de agrotóxicos por brasileiro.

A legislação que regulamenta a utilização de agrotóxicos no Brasil se respalda em complexas medidas de uso seguro idealizado pelas indústrias químicas a partir de 1986, em decorrência do aumento dos casos de intoxicação. Estabeleceram então, padrões de conduta para o comércio, listando diretrizes para governos, indústrias, empregadores e trabalhadores rurais. As medidas visam o controle dos riscos envolvidos na manipulação desses produtos criados para uma estrutura produtiva industrial do agronegócio. De acordo com a lei vigente no Brasil, para que possa ser correto e seguro o uso de agrotóxicos, são evidenciadas excessivas restrições para as atividades de aquisição, transporte, armazenamento, preparo e aplicação, descarte de embalagens vazias e lavagem de roupas e equipamentos contaminados (BRASIL, 1989; BRASIL, 2002).

Desse modo, fica implícito a desvantagem dos pequenos produtores, que induzidos pelo discurso produtivista, utilizam agrotóxicos sem conseguir arcar com os custos das medidas de uso seguro, tornando-se alvos da toxicidade desses produtos. ABREU e ALONZO (2014) afirmam que tais medidas tornam-se inviáveis e não comporta segurança aos trabalhadores rurais da agricultura familiar, objeto do seu estudo. Ainda, estes devem ser desresponsabilizados pelos danos e agravos envolvidos na utilização destes produtos.

A percepção de risco dos indivíduos que utilizam ou estão expostos a agrotóxicos também é determinante para que haja mais intoxicações. A naturalização do agrotóxico seja no campo ou em ambiente urbano, na capina química, dedetização de casas e na saúde pública, expõem as pessoas a uma falsa segurança, que mesmo utilizando Equipamentos de Proteção Individual, não é o suficiente para evitar a intoxicação humana e contaminação ambiental (ABREU, 2014; OLIVEIRA, 2018; PARANA, 2018).

A utilização de agrotóxicos é uma tecnologia inerente ao processo produtivo monocultor em larga escala, e ainda que existam legislações para o uso seguro, a fiscalização precária pode ser um fator determinante para ocorrência de danos na saúde dos trabalhadores, população e meio ambiente. Os estudos realizados em diversas regiões do Brasil revelam aumento de intoxicações agudas e de contaminação ambiental, entre outros impactos negativos, entendidos como consequência do incentivo fiscal público à utilização destes produtos, levando a questionar a eficácia da adoção deste paradigma de segurança (ABREU e ALONZO, 2014). 
Stephanie Sommerfeld de Lara

Wanderlei Antonio Pignati

Marta Gislene Pignatti

A agricultura do agronegócio e sua relação com a intoxicação aguda por agrotóxicos no Brasil

Luís Henrique da Costa Leão Jorge Mesquita Huet Machado

Figura 1 - A) Área plantada de monocultivos agrícolas e consumo de agrotóxicos em 2015 (PIGNATI et al., 2017) e B) incidências médias de intoxicação por agrotóxicos agrícolas nas Unidades Federadas, Brasil, durante o período de 2012-2015.
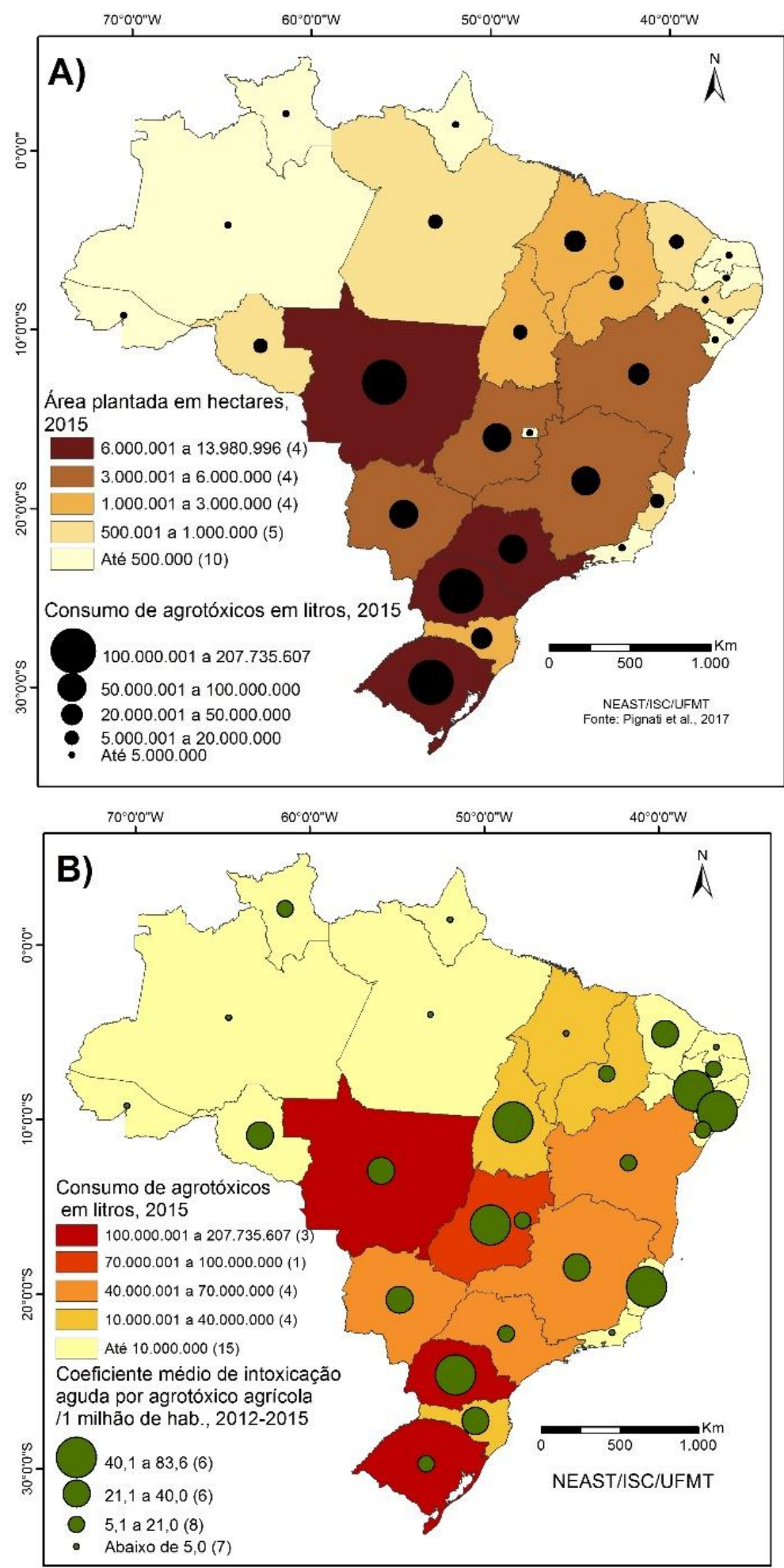


\section{Distribuição espacial do uso de agrotóxicos agrícolas e as intoxicações em Mato Grosso}

O Mato Grosso, um dos maiores produtores de grãos e bovinos do país (MATO GROSSO, 2016b), utilizou cerca de 207 milhões de litros de agrotóxicos em seus 13 milhões de hectares de monocultivos agrícolas em 2015, liderando o uso desses produtos no país e adquirindo a maior exposição ambiental a agrotóxicos, com 65 litros por habitante (Tabela 3).

O uso alarmante de agrotóxicos em 16 municípios da região central e sudeste do Mato Grosso (Sorriso, Sapezal, Campo Novo do Parecis, Nova Mutum, Nova Ubiratã, Diamantino, Campo Verde, Primavera do Leste, Querência, Lucas do Rio Verde, Campos de Júlio, Canarana, Brasnorte, Itiquira, Ipiranga do Norte e Paranatinga, respectivamente), que utilizaram mais de 4 milhões de litros de agrotóxicos mostra que cada um tiveram o consumo mais elevado que o estado de Pernambuco, por exemplo, e de outros 10 estados (Figura 2A).

Em relação à ocorrência das intoxicações agudas por agrotóxicos agrícolas, o ranking brasileiro aponta o Mato Grosso em $11^{\circ}$ lugar, embora ocupe a $1^{\text {a }}$ posição no consumo de agrotóxicos (Tabela 3 ). As incidências variaram em até 74 casos a cada 100 mil habitantes entre os municípios do estado, onde 57 deles estiveram acima da média estadual de aproximadamente 3 casos a cada 100 mil habitantes. Os municípios com as maiores incidências foram: Planalto da Serra (74,8/100 mil hab.), Reserva do Cabaçal $(38,2)$, Santa Carmem $(35,4)$, Nova Santa Helena $(35,3)$ e Santo Antônio do Leste $(34,6)$.

Ainda que as incidências do agravo possam ser calculadas para apontar locais de maior ocorrência, tornam-se insuficientes para expressar a realidade epidemiológica local em virtude da subnotificação. Assim sendo, FARIA et al. (2007) e PIGNATI et al., (2017) enfatizam o uso de indicadores de exposição química e previsão de impactos que não dependam apenas de dados oficiais de intoxicação, sendo que a associação desses dados tem sido uma estratégia relevante para priorizar locais, ações e investigar subnotificações de envenenamentos.

Pesquisas científicas realizadas em Mato Grosso demonstraram que a parcela mais significativa da contaminação por agrotóxicos em humanos e meio ambiente se concentra nas regiões de maior produção de monocultivos agrícolas de soja, milho, algodão e cana, que compõe $94 \%$ das lavouras no território. Trata-se de uma exposição impositiva a agrotóxicos, pois tanto os trabalhadores inseridos no agronegócio como moradores da região estão expostos a vários tipos desses produtos, que estão sendo detectados nos fluidos corporais leite materno, sangue e urina, e também no ar que respiram, água que bebem e alimentos que consomem, inclusive outros animais (MOREIRA et al., 2012; BELO et al., 2012; PALMA, 2014; OLIVEIRA, 2018; BESERRA, 2017; PIGNATI et al., 2017).

De forma geral, a intoxicação por agrotóxicos pode afetar a saúde a médio e longo prazo nos sistemas nervoso, endócrino, hematopoiético e reprodutivo, e ainda órgãos como olhos, pele, rins e fígado, além de aumentar a incidência de câncer, transtornos psíquicos, depressão e suicídios. Estes prejuízos na saúde e ambiente tem sido descritos em artigos científicos contidos nas revisões de literatura de Mostafalou e Abdollahi (2017) e Lopes e Albuquerque (2018). 
A agricultura do agronegócio e sua relação com a intoxicação aguda por agrotóxicos no Brasil

Stephanie Sommerfeld de Lara

Wanderlei Antonio Pignati Marta Gislene Pignatti

Luís Henrique da Costa Leão Jorge Mesquita Huet Machado

Figura 2 - A) Área plantada de monocultivos e consumo de agrotóxicos em 2015 (PIGNATI et al., 2017) e B) incidências médias de intoxicação por agrotóxicos nos municípios do Mato Grosso, Brasil, 2012 a 2015.

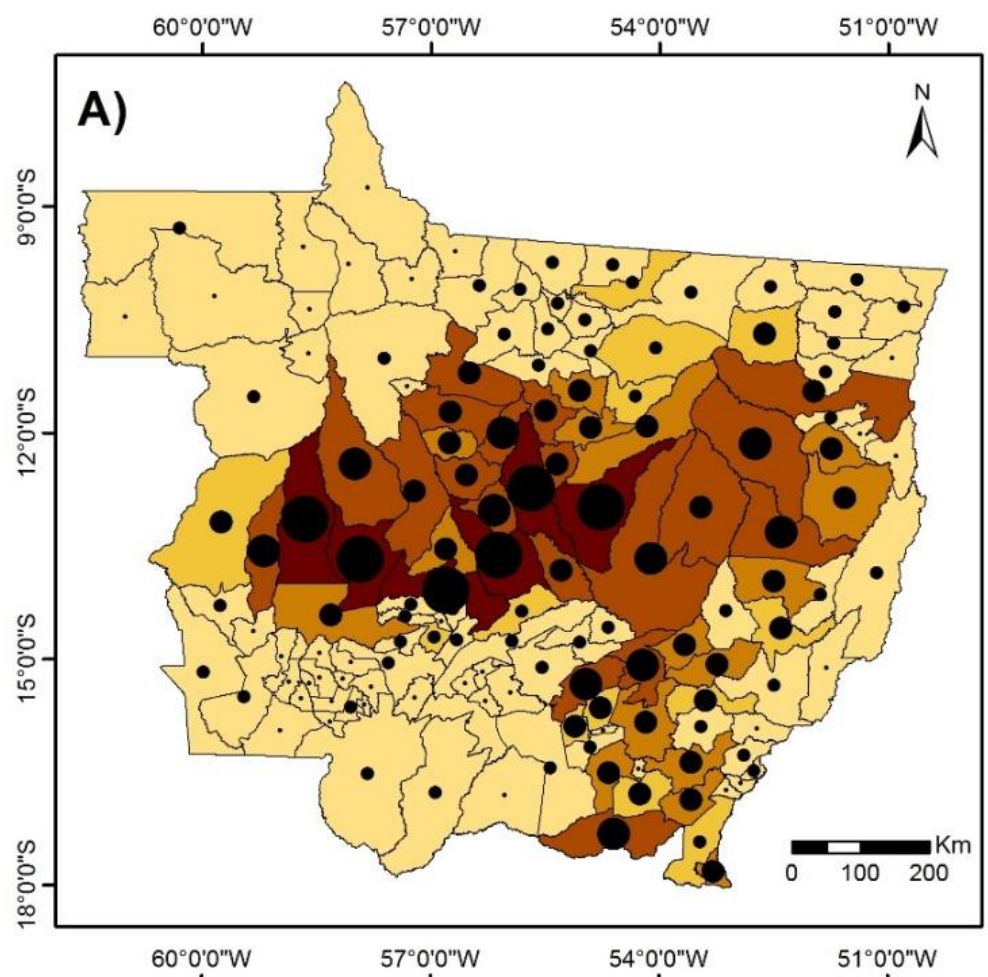

Área plantada de monocultivos (ha), 2015
500.001 a 1.083 .993 (6)
200.001 a $500.000(19)$
100.001 a 200.000 (16)
50.001 a $100.000(13)$
Abaixo 50.000 (87)

Consumo de agrotóxicos em litros, 2015
7.000 .001 a 14.635 .235 (6)
- 4.000 .001 a 7.000 .000 (10)
- 1.000 .001 a $4.000 .000(32)$
- 100.001 a $1.000 .000(52)$
- Abaixo de 100.000 (41)

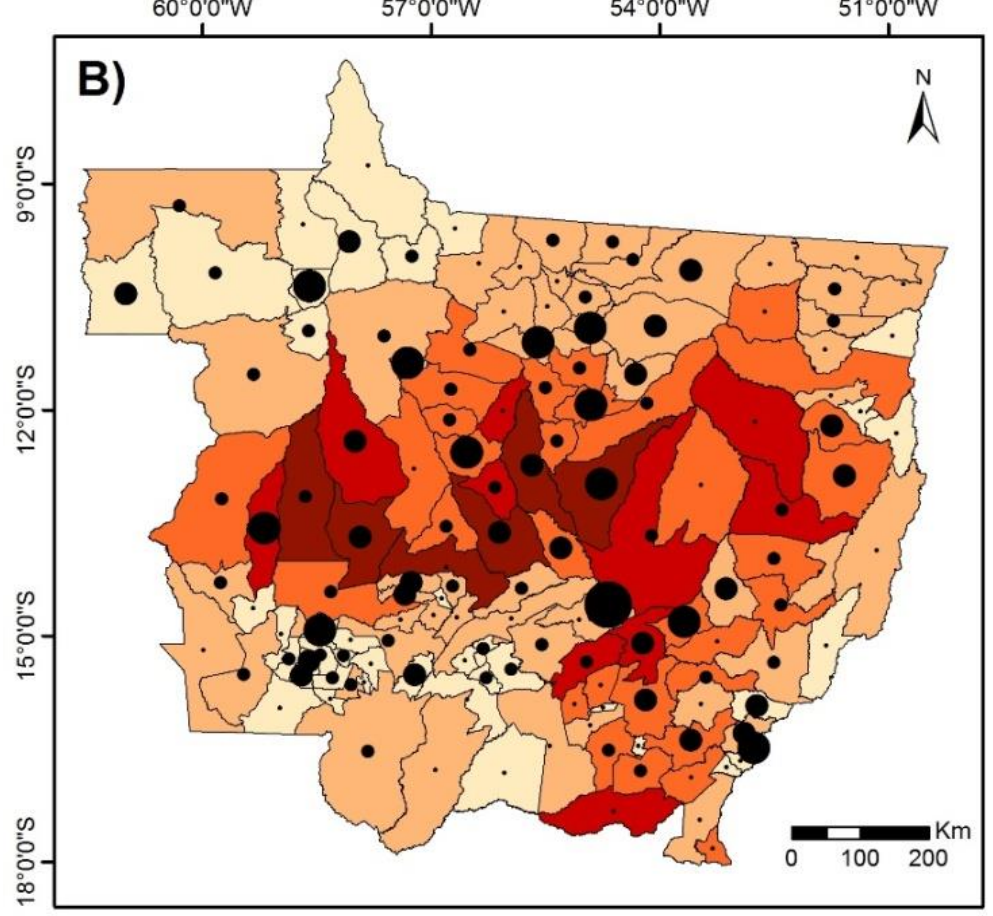

Consumo de agrotóxicos em litros, 2015
7.000 .001 a $14.635 .235(6)$ 4.000 .001 a $7.000 .000(10)$ 1.000 .001 a $4.000 .000(32)$ 100.001 a $1.000 .000(52)$ Abaixo de 100.000 (41)

Coeficiente médio de intoxicação aguda por agrotóxicos agrícolas /100 mil hab.2012-2015

- 45,1 a $74,8(1)$
20,1 a $45,0(11)$
- 5,1 a $20,0(23)$
- Munaixo de $5,0(48)$
Mucípio silencioso (58)




\section{Associação entre indicadores ambientais e de saúde}

Para confirmar a hipótese de associação entre o consumo, exposição ambiental a agrotóxicos agrícolas com a ocorrência de intoxicação aguda, foi correlacionado os indicadores ambientais com o de saúde. A correlação de Spearman constatou que os indicadores ambientais foram significativos e positivos em relação ao indicador de saúde (Tabela 4), ou seja, o aumento do consumo de agrotóxicos resultou em aumento nas incidências de intoxicações entre as Unidades Federadas ( $p$-valor 0,01 e força de associação de 48\%). Da mesma forma, os estados com as maiores exposições ambientais da população a agrotóxicos estiveram correlacionados as maiores incidências, confirmado pelo $p$-valor de 0,00 e força de associação de 52\%.

Para os municípios de Mato Grosso, a correlação entre o consumo de agrotóxicos e as incidências médias de intoxicação foi significativa ao p-valor de $0,01 \mathrm{com}$ força de associação de $21 \%$. A exposição ambiental correlacionado as incidências também apresentou significância, onde o $p$ valor adquirido foi 0,01 com coeficiente de correlação de 20,4\% (tabela 4).

Tabela 4 - Correlação de Spearman entre indicadores ambientais e de saúde nas Unidades Federadas e municípios de Mato Grosso, 2012-2015.

\begin{tabular}{|c|c|c|c|c|}
\hline $\begin{array}{l}\text { Indicador de saúde } \\
\text { (y) }\end{array}$ & Unidade de análise (n) & Indicador ambiental (x) & $\begin{array}{l}\text { Coeficiente } \quad \text { de } \\
\text { correlação }\end{array}$ & $\begin{array}{l}\text { p- } \\
\text { valor }\end{array}$ \\
\hline \multirow{2}{*}{$\begin{array}{l}\text { Coeficiente médio de } \\
\text { incidência de intoxicação } \\
\text { aguda por agrotóxico } \\
\text { agrícola por } 1 \text { milhão de } \\
\text { hab. }\end{array}$} & \multirow{2}{*}{ Unidades Federadas (27) } & $\begin{array}{l}\text { Consumo de agrotóxicos em } \\
\text { litros, } 2015\end{array}$ & $48,5 \%$ & 0,01 \\
\hline & & $\begin{array}{l}\text { Exposição ambiental a } \\
\text { agrotóxicos } 2015\end{array}$ & $52,0 \%$ & 0,00 \\
\hline \multirow{2}{*}{$\begin{array}{l}\text { Coeficiente médio de } \\
\text { incidência de intoxicação } \\
\text { aguda por agrotóxico } \\
\text { agrícola nos municípios } \\
\text { de Mato Grosso, 2012- } \\
2015 \text {, por } 100 \text { mil hab. }\end{array}$} & \multirow[b]{2}{*}{$\begin{array}{c}\text { Municípios de Mato Grosso } \\
(141)\end{array}$} & $\begin{array}{l}\text { Consumo de agrotóxicos em } \\
\text { litros, } 2015\end{array}$ & $21,0 \%$ & 0,01 \\
\hline & & $\begin{array}{l}\text { Exposição ambiental } \\
\text { agrotóxicos } 2015\end{array}$ & $20,4 \%$ & 0,01 \\
\hline
\end{tabular}

Este estudo constatou o crescimento da ocorrência e incidência das intoxicações agudas por agrotóxicos ao longo dos anos, com associação positiva e significativa deste agravo ao consumo e exposição ambiental a agrotóxicos utilizado nas lavouras agrícolas. Conclui-se que as regiões agrícolas do agronegócio são relevantes para contribuir na ocorrência das intoxicações agudas. Isto pode ser explicado pelo maior número de trabalhadores e população em geral envolvidos na cadeia do agronegócio e expostos aos produtos, pela naturalização do uso de agrotóxicos nessas regiões agrícolas, gerando a manipulação imprudente, descumprimento de normas e legislações vigentes, e até mesmo intoxicações na população decorrentes de derivas da pulverização aérea e por tratores (PIGNATI et al., 2007; DUTRA e SOUZA, 2017).

Ambos indicadores ambientais (consumo e exposição ambiental a agrotóxicos) demonstraram ser eficazes para alocar prioridades de ações da Vigilância em Saúde de Populações Expostas a Agrotóxicos, pois sinaliza locais onde possa existir a subnotificação de intoxicações agudas e crônicas. Os achados do presente estudo desafiam órgãos responsáveis para a "Vigilância do Desenvolvimento", através de fiscalização e atuação contínua de ações nestas áreas de elevada produção agrícola. 


\section{CONSIDERAÇÕES FINAIS}

Tanto o uso de agrotóxicos quanto as intoxicações no Brasil aumentaram durante os anos de 2007 a 2016. Este agravo continuou ocupando o segundo lugar de ocorrência dentre todas as intoxicações exógenas, e a primeira posição em letalidade. Entre o grupo de agrotóxicos, os raticidas e agrotóxicos agrícolas foram os agentes tóxicos que mais ocasionaram intoxicações agudas no Brasil, e dobraram de valor no período estudado. O Mato Grosso, Paraná e Rio Grande do Sul foram destaque para o uso de agrotóxicos, enquanto que Espirito Santo, Tocantins e Paraná para as maiores incidências de intoxicações. Foi associado positivamente e significativamente o agravo ao consumo e exposição ambiental a agrotóxicos nas Unidades Federadas e municípios de Mato Grosso. Concluiu-se que os locais com elevada produção agrícola do agronegócio foram relevantes na contribuição da ocorrência das intoxicações agudas.

Por tratar-se de uma análise de aglomerados, sugerimos para estudos futuros uma investigação de nível individual sobre a ocorrência da intoxicação, pois fica implícito neste artigo que as intoxicações estão decorrendo de lavouras agrícolas do agronegócio, contrariando as literaturas que apontam o pequeno e médio produtor agrícola como suscetível a intoxicação pela inacessibilidade e/ou descumprimento de normas e legislações vigentes devido os custos, e até mesmo, percepções de risco (FONSECA, 2007; ABREU, 2014).

Em escala nacional, a saúde da população e preservação do meio ambiente está sujeito a ações governamentais. A fragilização de leis e políticas dos agrotóxicos com o único objetivo de favorecer a economia poderá agravar o cenário das intoxicações no Brasil. Neste sentido, o cumprimento da legislação, normas nacionais e estaduais devem fazer-se cumprir pelos órgãos de fiscalização e sociedade civil.

Medidas de proteção coletiva precisam ser urgentemente implantadas, pois apenas um episódio de intoxicação é capaz de ocasionar diminuição cognitiva, dentre outros males (ROSENSTOCK et al. 1991; ONU, 2017). A implantação e efetividade da Vigilância em Saúde de Populações Expostas a Agrotóxicos (VSPEA) nos estados brasileiros e principalmente nos municípios prioritários de Mato Grosso é essencial. Deve-se iniciar pelas regiões monocultoras de alta produção, onde se utiliza mais agrotóxicos e se observa maior incidência de intoxicações em trabalhadores e população. Os profissionais de saúde necessitam estar capacitados para que possam diagnosticar intoxicações agudas e crônicas.

É necessário que a Vigilância em Saúde trabalhe em conjunto com os demais órgãos, estimulando o princípio da precaução, visando reduzir o uso de agrotóxicos no Brasil, proibir o uso dos altamente tóxicos e extremamente tóxicos, e os já proibidos na União Europeia, como vem sendo proposto pelo Programa Nacional de Redução de Agrotóxicos (PRONARA) e projeto de lei da Política Nacional de Redução de Agrotóxicos (PNaRA).

\section{REFERÊNCIAS}

ABREU, P. H. B. O agricultor familiar e o uso (in)seguro de Agrotóxicos no município de

Lavras, MG. 2014. 205 f. Dissertação (Mestrado em Saúde Coletiva) - Universidade Estadual de Campinas, Faculdade de Ciências Médicas, Campinas, 2014.

ABREU, P. H. B.; ALONZO, H. G. A. Trabalho rural e riscos à saúde: uma revisão sobre o "uso seguro" de agrotóxicos no Brasil. Ciênc. saúde coletiva, v. 19, n. 10, p. 4197-4208, 2014.

https://doi.org/10.1590/1413-812320141910.09342014

ATREYA, K. Health costs from short-term exposure to pesticides in Nepal. Soc Sci Med., v. 67, n. 4, p. 511-9, 2008. https://doi.org/10.1016/i.socscimed.2008.04.005

BELO, M. S. S. P. et al. Uso de agrotóxicos na produção de soja do estado do Mato Grosso: um estudo preliminar de riscos ocupacionais e ambientais. Rev. bras. saúde ocup., v. 37, n. 125, p. 78-88, 2012. https://doi.org/10.1590/S0303-76572012000100011 
BESERRA, L. Agrotóxicos, vulnerabilidades socioambientais e saúde: uma avaliação participativa em municípios da bacia do rio Juruena, Mato Grosso. 2017. 137 f. Dissertação (Mestrado em Saúde Coletiva) - Universidade Federal de Mato Grosso, Instituto de Saúde Coletiva. Cuiabá 2017.

BOCHNER, R. Sistema Nacional de informações Tóxico-Farmacológicas - SINITOX e as intoxicações humanas por agrotóxicos no Brasil. Ciênc Saúde Coletiva., v. 12, n. 1, p. 73-89, 2007. https://doi.org/10.1590/S1413-81232007000100012

BOCHNER, R. Óbito ocupacional por exposição a agrotóxicos utilizado como evento sentinela: quando pouco significa muito. Vigil. sanit. Debate, v.3, n. 4, p. 39-49, 2015.

https://doi.org/10.3395/2317-269x.00364

BOMBARDI, L. M. Agrotóxicos e agronegócio: arcaico e moderno se fundem no campo brasileiro. In: Direitos humanos no Brasil: Relatório da Rede Social de Justiça e Direitos Humanos. p. 75-86, 2012.

BRASIL. Decreto Federal n. 4074 de 4 de janeiro de 2002. Regulamenta a Lei no 7.802, de 11 de julho de 1989, que dispõe sobre a pesquisa, a experimentação, a produção, a embalagem e rotulagem, o transporte, o armazenamento, a comercialização, a propaganda comercial, a utilização, a importação, a exportação, o destino final dos resíduos e embalagens, o registro, a classificação, o controle, a inspeção e a fiscalização de agrotóxicos, seus componentes e afins, e dá outras providências.

BRASIL. Lei Complementar no 87/1996 de 13 de setembro de 1996. Dispõe sobre o imposto dos Estados e do Distrito Federal sobre operações relativas à circulação de mercadorias e sobre prestações de serviços de transporte interestadual e intermunicipal e de comunicação, e dá outras providências (Lei Kandir). Diário Oficial da União, Brasília, seção 1, p. 18.261, 16 set. 1996.

BRASIL. Lei no 7.802, de 11 de julho de 1989. Dispõe sobre a pesquisa, a experimentação, a produção, a embalagem e rotulagem, o transporte, o armazenamento, a comercialização, a propaganda comercial, a utilização, a importação, a exportação, o destino final dos resíduos e embalagens, o registro, a classificação, o controle, a inspeção e a fiscalização de agrotóxicos, seus componentes e afins, e dá outras providências. Diário Oficial da União. 12 jul. 1989.

BRASIL. Ministério da Saúde. Agência Nacional de Vigilância Sanitária. Nota sobre o uso de agrotóxicos em área urbana, 2015. Disponível em: <http://portal.anvisa.gov.br/resultado-debusca?p_p_id =101\&p_p_lifecycle $=0 \&$ \&_p_state $=$ maximized\&p_p_mode $=v i e w \& p \_p \_c o l \_i d=c o l u m n$ 1\&p_p_col_count $=1 \&$ _101_struts_action=\%2Fasset_publisher\%2Fview_content $\&$ _101_assetEntry Id $=509166 \&$ 101_type $=$ content\&_101_urlTitle=uso-de-agrotoxicos-em-area-

urban\&inheritRedirect=true $>$. Acesso: 05 janeiro 2019.

BRASIL. Ministério da Saúde. Dicas em saúde: intoxicação por agrotóxicos. Folder, 2006.Disponível em:< http://bvsms.saude.gov.br/bvs/dicas/108agrotox.html>. Acesso: 06 agosto 2019.

BRASIL. Ministério da Saúde. Secretaria de Vigilância em Saúde. Boletim Epidemiológico no 50 . Casos notificados de intoxicações exógenas relacionados ao glifosato no Brasil, no período de 2007 a 2016. V. 49. Novembro de 2018b. 10 p. Disponível em: <

http://portalarquivos2.saude.gov.br/images/pdf/2018/dezembro/04/BE-2018-31-Glifosato.pdf>. Acesso: 06 agosto 2019.

BRASIL. Ministério da Saúde. Secretaria de Vigilância em Saúde. Departamento de Saúde Ambiental e Saúde do Trabalhador. Coordenação Geral de Vigilância em Saúde Ambiental. Documento Orientador para a Implementação da Vigilância em Saúde de Populações Expostas a Agrotóxicos. 1. ed. - Brasília: Ministério da Saúde, 2012. 133 p. Disponível em:< 
http://renastonline.ensp.fiocruz.br/sites/default/files/arquivos/recursos/Documento\%20orientador\% 20Vig\%20Pop\%20Agrotox_Vigipeq_completo2013.pdf>. Acesso: 06 agosto 2019.

BRASIL. Ministério da Saúde. Secretaria de Vigilância em Saúde. Diretrizes nacionais para a vigilância em saúde de populações expostas a agrotóxicos. Brasília: Ministério da Saúde; 2016. 26 p. Disponível em:<http://www.agroecologia.gov.br/sites/default/files/publicacoes/Diretrizes-VSPEA.pdf>. Acesso: 06 agosto 2019.

BRASIL. Ministério da Saúde. Departamento de informática do Sistema Único de Saúde (DATASUS). Sistema de Informação de Agravos de Notificação - SINAN. Tabulação de dados. Intoxicação por agrotóxico e exógena. Disponível em < http://www2.datasus.gov.br/DATASUS/index.php?area=0203\&id=29892176\&VObj=http://tabnet.da tasus.gov.br/cgi/deftohtm.exe?sinannet/cnv/Intox>. Acesso em: 20 março 2018a.

CARNEIRO, F.F et al. Dossiê ABRASCO: Um alerta sobre os impactos dos agrotóxicos na saúde. São Paulo: Expressão Popular; 2015. 624 p.

DARONCHO, L. Capitulo 3. O direito e a Saúde dos Trabalhadores expostos a agrotóxicos. P.87 a 116. In: Folgado CAR. Direito e agrotóxico. Reflexões críticas sobre o sistema normativo. Lumen Juris, 312 p., 2017.

DUTRA, R. M. S.; SOUZA, M. M. O. Impactos negativos do uso de agrotóxicos à saúde humana. Hygeia, v. 13, n. 24, p. 127-140, 2017.

FARIA, N. M. X.; FASSA, A. G.; FACCHINI, L. A. Intoxicação por agrotóxicos no Brasil: os sistemas oficiais de informação e desafios para realização de estudos epidemiológicos. Ciênc. saúde coletiva, v. 12, n. 1, p. 25-38, 2007. https://doi.org/10.1590/S1413-81232007000100008

FONSECA, M. G. U. et al. Percepção de risco: maneiras de pensar e agir no manejo de agrotóxicos. Ciênc. saúde coletiva, v. 12, n. 1, p. 39-50, 2007. https://doi.org/10.1590/S1413$\underline{81232007000100009}$

INSTITUTO BRASILEIRO DO MEIO AMBIENTE E DOS RECURSOS NATURAIS RENOVÁVEIS (IBAMA). Instrução Normativa Conjunta № 11, de 30 de Junho de 2015. Disponível em:< http://www.ibama.gov.br/sophia/cnia/legislacao/IBAMA/IN0011-300615.pdf>. Acesso em: 07 agosto 2019.

JANK, M. S.; NASSAR, A. M.; TACHINARDI, M. H. Agronegócio e comércio exterior brasileiro. Revista USP, v. 64, p. 14-27, 2005. https://doi.org/10.11606/issn.2316-9036.v0i64p14-27

JEKEL, J. F.; KATZ, D. L.; ELMORE, J. G. Epidemiologia Bioestatística e Medicina Preventiva. $2^{\circ}$ ed. Porto Alegre: Artmed, 2005.

LOPES, C. V. A.; ALBUQUERQUE, G. S. C. Agrotóxicos e seus impactos na saúde humana e ambiental: uma revisão sistemática. Saúde debate, v. 42, n. 117, p. 518534, 2018. https://doi.org/10.1590/0103-1104201811714

MALASPINA, F. G.; ZINILISE, M. L.; BUENO, P. C. Perfil epidemiológico das intoxicações por agrotóxicos no Brasil, no período de 1995 a 2010. Cad Saúde Coletiva, v. 19, n. 4, p. 425-34, 2011.

MATO GROSSO (Estado). Aspectos Geográficos do Estado de Mato Grosso. Disponível em: <http://turismo.sedtur.mt.gov.br/imprime.php?cid=83\&sid=74>. Acesso em: 25 outubro 2016.

MEDRONHO, R. A. et al. Epidemiologia. 2ª ed. Rio de Janeiro: Atheneu, 2009. 
MOREIRA, J. C. et al. Contaminação de águas superficiais e de chuva por agrotóxicos em uma região de Mato Grosso. Ciência \& Saúde Coletiva, v. 17, n. 6, p. 1557-1568, 2012.

https://doi.org/10.1590/S1413-81232012000600019

MOSTAFALOU, S.; ABDOLLAHI, M. Pesticides: an update of human exposure and toxicity. Arch Toxicol., v. 91, n. 2, p. 549-599, 2017. https://doi.org/10.1007/s00204-016-1849-x

NASRALA, E.; LACAZ, F.; PIGNATI, W. Vigilância em saúde e agronegócio: impactos dos agrotóxicos na saúde e ambiente. Perigo à vista. Ciência \& Saúde Coletiva, v. 29, n. 12, p. 47094718, 2014. https://doi.org/10.1590/1413-812320141912.03172013

OLIVEIRA, L. K. et al. Processo sócio-sanitário-ambiental da poluição por agrotóxicos na bacia dos rios Juruena, Tapajós e Amazonas em Mato Grosso, Brasil.Saude soc, v. 27, n. 2, p. 573587, 2018. https://doi.org/10.1590/s0104-12902018170904

OMS. World Health Organization. Public Health Impact of Pesticides used in agriculture. Geneva, 1990. 128 p.

ORGANIZAÇÃO DAS NAÇÕES UNIDAS (ONU). United Nations. Report of the Special Rapporteur on the right to food. Human Rights Council. Human Rights Council, Session 34, n. 48. 24 January 2017.

ORGANIZAÇÃO PAN-AMERICANA DA SAÚDE (OPAS). Representação no Brasil. Manual de vigilância da Saúde de populações expostas a agrotóxicos. Brasília, Organização Pan-Americana da Saúde, 1997. 69 p.

PALMA, D. C. A et al. Simultaneous determination of different classes of pesticides in breast milk by solid-phase dispersion and GC/ECD. Journal of the Brazilian Chemical Society, v. 25, n. 8, p. 1419-1430, 2014. https://doi.org/10.5935/0103-5053.20140124

PARANÁ (Estado). Secretaria de Estado da Saúde do Paraná. Superintendência de Vigilância em Saúde Centro Estadual de Saúde do Trabalhador. Protocolo de avaliação das intoxicações crônicas por agrotóxicos. Curitiba, 2013. 75 p.

PARANÁ (Estado). Secretaria de Estado da Saúde do Paraná. Superintendência de Atenção à Saúde. Linha Guia da Atenção às Populações Expostas aos Agrotóxicos. - 1 ed. - Curitiba: SESA, 2018. $72 \mathrm{p}$.

PELAEZ, V. et al. (des)coordenação de políticas para a indústria de agrotóxicos no Brasil. Revista Brasileira de Inovação, v. 14, n. esp., p. 153-178, 2015. https://doi.org/10.20396/rbi.v14i0.8649104

PIGNATI, W. A. et al. Distribuição espacial do uso de agrotóxicos no Brasil: uma ferramenta para a Vigilância em Saúde. Ciênc. saúde coletiva, v. 22, n. 10, p. 3281-3293, 2017. https://doi.org/10.1590/1413-812320172210.177422017

PIGNATI. W.; MACHADO, J. M. H.; CABRAL, J. F. Acidente rural ampliado: o caso das "chuvas" de agrotóxicos sobre a cidade de Lucas do Rio Verde - MT. Ciênc. saúde coletiva, v. 12, n. 1, p. 105-114, 2007. https://doi.org/10.1590/S1413-81232007000100014

ROSENSTOCK, L. et al. Chronic central nervous system effects of acute organophosphate pesticide intoxication. The Lancet., v. 338, n. 8761, p. 223-227, 1991.

https://doi.org/10.1016/0140-6736(91)90356-T 
SOARES, W. L.; PORTO, M. F. S. Uso de agrotóxicos e impactos econômicos sobre a saúde.

Rev. Saúde Pública., v. 46, n. 2, p. 209-217, 2012. https://doi.org/10.1590/S0034-

$\underline{89102012005000006}$

WHO. World Health Organization. Poisoning Prevention and Management. Disponível em: <http://www.who.int/ipcs/poisons/en/>. Acesso em: 5 março 2018. 